\title{
Expression profile of spermatogenesis associated genes in male germ cells during postnatal development in mice
}

\author{
Jin Seop Ahn ${ }^{1}$, Hyun-Sung Ryu ${ }^{2}$, Sang-Eun Jung ${ }^{1}$, Beom-Jin Shin ${ }^{1}$, Jong-Hyun Won ${ }^{1}$, Tea Gun Um ,
} Huijo $\mathrm{Oh}^{1}$, Seo-Hee $\mathrm{Kim}^{1}$ and Buom-Yong Ryu ${ }^{1, *}$

${ }^{1}$ Department of Animal Science and Technology, Chung Ang University, Anseong, 17546, Korea

${ }^{2}$ Department of Biosciences, Durham University, Durham DH1 3LE, UK

Received November 10, 2020

Revised November 24, 2020

Accepted November 25, 2020

*Correspondence

Buom-Yong Ryu

E-mail: byryu@cau.ac.kr

ORCID

https://orcid.org/0000-0002-8349-7299

\begin{abstract}
Spermatogonial stem cells are self-renewal and differentiate into sperm in post-pubertal mammals. There exists a balance between the self-renewal and differentiation in the testes. Spermatogonial stem cells make up only $0.03 \%$ of testicular cells in adult mice. These cells maintain sperm production by differentiating after puberty. Therefore, analyzing the expression of genes associated with spermatogenesis is critical for understanding differentiation. The present study aimed to establish the postnatal period of cells in relation to spermatogenesis. To study the expression of differentiated and undifferentiated marker genes in enriched spermatogonial stem cells, in vitro culture was performed and cells from pup (6-8-day-old) and adult (4-months-old) testicular tissues were isolated. As a result, undifferentiated genes, Pax7, Plzf, GFRa1, Etv5 and Bcl6b, were highly increased in cultured spermaotogonial stem cells compared with pup and adult testicular cells. On the other hands, differentiated gene, $c$-kit was highly increased in adult testicular cells, Also Stra8 gene was highly increased in pup and adult testicular cells. This study provides a better understanding of spermatogenesis-associated gene expression during postnatal periods.
\end{abstract}

Keywords: adult testicular cells, gene expression, pup testicular cells, spermatogenesis, spermatogonial stem cells

\section{INTRODUCTION}

Spermatogonial stem cells (SSCs) are the foundation of spermatogenesis in the testes and are essential for male fertility (Phillips et al., 2010; Park et al., 2014). SSCs have two major roles; first, they maintain a pool of self-renewing cells, allowing the proliferation of stem cell populations, and second, they support sperm production by the spermatogonial differentiation of SSCs in post-pubertal males (Oatley and Brinster, 2008). SSCs comprise only $0.03 \%$ of total germ cells in mice (Phillips et al., 2010). In postnatal mouse testes, SSCs are located on the basement membrane of seminiferous tubules surrounded by Sertoli cells (de Rooij, 1973).

Spermatogenesis appears as dual division; first, $A_{\text {single }}$ spermatogonia $\left(A_{s}\right)$ is divided into $A_{\text {pair }}\left(A_{p r}\right.$, chain of two), $A_{\text {aligned } 4}\left(A_{\text {al4 }}\right.$, chain of four $), A_{\text {aligned } 8}\left(A_{\text {al8 }}\right.$, chain of eight $)$, and $A_{\text {aligned16 }}\left(A_{\text {al16}}\right.$, chain of sixteen) through mitosis. Af- 
ter differentiation to A1 spermatogonia, A2, A3, A4, intermediate (In), and B spermatogonia as well as meiotic spermatocytes are generated. Meiotic spermatocytes are divided into secondary spermatocytes and round spermatids, which are produced in mature sperm, by secondary meiosis (Valli et al., 2015).

$A_{s}$ is a function of division to new $A_{s}$ spermatogonia and maintains an undifferentiated spermatogonia state (de Rooij, 1973). In addition, $A_{\mathrm{pr}}$ and $A_{\mathrm{al} 4}$ self-renew to produce single spermatogonia by complete cytokinesis (de Rooij and Griswold, 2012). Undifferentiated spermatogonia in mouse testes express numerous self-renewal genes, such as paired box 7 (Pax7), promyelocytic leukemia zinc finger (Plzf), GDNF-family receptor $\alpha 1$ (GFRa1), Ets variant gene 5 (Etv5), and B-cell CLL/lymphoma 6, member B (Bcl6b) (Costoya et al., 2004; Buageaw et al., 2005; Schlesser et al., 2008; Ishii et al., 2012; Aloisio et al., 2014), while proto-oncogene c-kit ( $c-k i t)$ and stimulated by retinoic acid 8 (Stra8) are expressed by all differentiated spermatogonia (Yoshinaga et al., 1991; Zhou et al., 2008). The Pax 7 gene is specifically expressed in $A_{s}$ spermatozoa (Aloisio et al., 2014). The large ETS family of transcription factors, Etv5, is important in SSC development. Etv5 gene deficiency causes loss of all germ cells and the Sertoli cell-only phenotype in mice by 10 weeks after birth (Chen et al., 2005). The c-kit gene is expressed in type A, In, and type B spermatogonia. Also, mutated c-kit gene is generating loss of melanocyte and germ cells (Sorrentino et al., 1991). The Stra8 gene is expressed in germ cells from mitosis to meiosis and plays a key role during initial meiosis (Giuili et al., 2002).

In mice, SSCs directly develop to A1 spermatogonia on day 6 after birth, and spermatogenesis is completed during the differentiation of SSCs within 3 weeks in mice (Culty, 2009). Therefore, this study aimed to identify the cells involved in the spermatogenesis period and analyze the gene expression of spermatogenesis-associated marker genes. Therefore, we established a culture of SSCs (enriched undifferentiated SSCs), pup testicular cells (PTCs, pre-puberty), and adult testicular cells (ATCs, postpuberty) for gene expression analysis.

\section{MATERIALS AND METHODS}

\section{Animals}

Male C57/BL6J-TG-EGFP (Jackson Laboratory, Bar Har- bor, Maine, USA) and female C57/BL6J mice(Samtako Bio, Osan, Gyeonggi-do, Korea) were used. Six-week-old female mice were obtained separately. All animal experiments were approved by the Institutional Animal Care and Use Committee of Chung-Ang University (no. 202000057) and were carried out in accordance with the Guide for the Care and Use of Laboratory Animals published by the NIH. All animals had free access to food and water during the experiments.

\section{Isolation and culture of mouse spermatogonial stem cells}

Mouse SSCs were isolated according to a previously described method (Oatley et al., 2007). Briefly, 6-8-day-old male mice were euthanized using carbon dioxide. Seminiferous tubules were isolated from the testes and washed in DPBS. After treatment with 2:1 (Invitrogen, Carlsbad, CA, USA) of $0.025 \%$ typsin-EDTA (Invitrogen, Carlsbad, CA, USA) and $7 \mathrm{mg} / \mathrm{mL}$ DNase I (Roche, Basel, Switzerland) at $37^{\circ} \mathrm{C}$ for $5 \mathrm{~min}$, single cells were recovered. Filtration was performed using a $40-\mu \mathrm{m}$ mesh, and centrifugation was then undertaken at $600 \times \mathrm{g}$ for $7 \mathrm{~min}$ at $4{ }^{\circ} \mathrm{C}$. The supernatant was then discarded, and a $30 \%$ Percoll gradient was applied to remove the erythrocytes and debris. For the purification of SSCs, the MACS method was used (Oatley and Brinster, 2006) using anti-Thy1 antibody microbeads (1:10, Miltenyi Biotech, Auburn, CA, USA) for 15 min at $4^{\circ} \mathrm{C}$. Thy1-positive cells were plated onto mitotically inactivated STO (SIM mouse embryo-derived thioguanine- and ouabain-resistant) feeder cells. SSC culturing was conducted based on a previously reported method (Jung et al., 2020a).

\section{Isolation of testicular cells}

Pup (6-8-day-old) and adult (4-month-old) male mice were euthanized and the testes were obtained. These were then decapsulated and treated with 2:1 (Invitrogen, Carlsbad, CA, USA) of $0.025 \%$ typsin-EDTA (Invitrogen, Carlsbad, CA, USA) and $7 \mathrm{mg} / \mathrm{mL}$ DNase I (Roche, Basel, Switzerland) at $37^{\circ} \mathrm{C}$ for $5 \mathrm{~min}$, and single cells were isolated. Filtration was performed using a $40-\mu \mathrm{m}$ mesh followed by centrifugation at $600 \times \mathrm{g}$ for $7 \mathrm{~min}$ at $4^{\circ} \mathrm{C}$. The erythrocytes and debris were then removed, and a 30\% Percoll gradient was applied followed by centrifugation at $600 \times$ $\mathrm{g}$ for $10 \mathrm{~min}$ at $4^{\circ} \mathrm{C}$. Cell pellets were then resuspended in Trizol reagent (Invitrogen) for cDNA synthesis. 


\section{Hematoxylin \& eosin staining}

The mouse testes were maintained in $4 \%$ formaldehyde overnight at $4{ }^{\circ} \mathrm{C}$. The fixed tissue was then embedded in paraffin, and paraffin sections $(5 \mu \mathrm{m})$ were deparaffinized in xylene and re-hydrated in serially diluted alcohol. The samples were then washed in running tap water for $5 \mathrm{~min}$, incubated in Mayer's hematoxylin solution for $1 \mathrm{~min}$, and washed in running tap water for $20 \mathrm{~min}$. The samples were moved to a jar filled with Eosin solution and incubated for $1 \mathrm{~min}$. After dehydration and clearing, the samples were visualized under a $\mathrm{Ni}-\mathrm{U}$ microscope (Nikon, Tokyo, Japan). NIS Elements imaging software (Nikon, Tokyo, Japan) was used for analysis.

\section{Immunohistochemistry}

For immunohistochemistry analysis, paraffin sections (5 $\mu \mathrm{m})$ were fixed in $4 \%$ paraformaldehyde, permeabilized with $0.1 \%$ Triton $\mathrm{X}-100$, and left for $1 \mathrm{~h}$ in blocking solution containing serum. Anti-VASA antibody (Santa Cruz Biotechnology, Dallas, TX, USA) was diluted to 1:100 in PBS and incubated overnight at $4{ }^{\circ} \mathrm{C}$. After washing with PBS containing Tween 20, the sections were incubated for $1 \mathrm{~h}$ with fluorescent conjugated secondary antibodies and visualized under a fluorescent microscope. DAPI was used for nuclei counterstaining.

\section{Quantitative reverse transcription polymerase chain reaction (qRT-PCR)}

Total RNA was isolated from SSCs and testicular cells using a PureLink ${ }^{\mathrm{TM}}$ RNA Mini Kit (Invitrogen, USA), according to the manufacturer's protocol. cDNA was synthesized from 1000 ng of total RNA using a SuperScript ${ }^{\circledR}$ IV FirstStrand Synthesis System (Invitrogen) and oligo-(dT) primers, according to the manufacturer's instructions. For qRT-PCR, $5 \mu \mathrm{L}$ of SYBR Green PCR Master Mix, $1 \mu \mathrm{L}$ of primers, and distilled water up to $20 \mu \mathrm{L}$ were used. Each cDNA was used as a template for PCR amplification in combination with designed gene-specific primers (Table 1). The assay was performed in triplicate using a 7500 Real-Time PCR System (Applied Biosystems, Carlsbad, CA, USA) in 96-well plates (Applied Biosystems). qRT-PCR was performed for two-step thermal cycling as follows: 40 cycles of $95^{\circ} \mathrm{C}$ for $20 \mathrm{~s}$ and $60^{\circ} \mathrm{C}$ for $60 \mathrm{~s}$, followed by a melting stage of $95^{\circ} \mathrm{C}$ for $15 \mathrm{~s}, 60^{\circ} \mathrm{C}$ for $60 \mathrm{~s}, 95^{\circ} \mathrm{C}$ for 30 $\mathrm{s}$, and $60^{\circ} \mathrm{C}$ for $15 \mathrm{~s}$. Expression levels were normalized to the amount of $G A P D H$, and data were analyzed using the $2^{-\Delta \Delta C \mathrm{t}}$ method.

\section{Statistical analysis}

All experiments were repeated at least thrice, and statistical analysis was performed using one-way analysis of variance with Tukey's honestly significant difference test as a post-hoc test, and the significance level was set at $p<0.05$. The results are expressed as the mean \pm SEM of triplicate independent samples.

\section{RESULTS}

\section{Identification of germ cells in mouse testes}

Mouse mitotic and meiotic germ cell markers, Vasa homologs (VASA, also known as DEAE-box helicase (DDX4)), were enriched in primordial germ cells and spermatogenic cells in mice (Toyooka et al., 2000). The VASA protein expression and subcellular localization of testes tissue were assessed in both PTCs and ATCs (Fig. 1A). In addition, qRT-PCR analysis showed significantly higher expression in ATCs compared with cultured SSCs and PTCs (Fig. 1B). These results indicated abundant amounts of germ cells in ATCs compared with cultured SSCs and PTCs.

Table 1. The sequence of primers for qRT-PCR analysis

\begin{tabular}{|c|c|c|}
\hline Gene & Forward $\left(5^{\prime}-3^{\prime}\right)$ & Reverse $\left(5^{\prime}-3^{\prime}\right)$ \\
\hline Vasa & GAGATTGCCTTCAGTACCTATGTG & GTGCTTGCCCTGGTAATTCT \\
\hline Pax7 & CTCAGTGAGTTCGATTAGCCG & AGACGGTTCCCTTTGTCGC \\
\hline Plzf & CACCTTCGCTCACATACAGG & ACTTCTTGCCACAGCCATTAC \\
\hline GFRa1 & GTGTGCAGATGCTGTGGACT & TTCAGTGCTTCACACGCACT \\
\hline Etv5 & CCCGGATGCACTCTTCTCTATG & TCGGATTCTGCCTTCAGGAA \\
\hline$B c / 6 b$ & TACTTCAAGGCTTCGCCTCTCT & CTACGTGTTCCATCTGCAAATAGG \\
\hline$c-k i t$ & AGAAGCAGATCTCGGACAGC & CATCACAGAAGCCAGAAGGAC \\
\hline Stra8 & GTTTCCTGCGTGTTCCACAAG & CACCCGAGGCTCAAGCTTC \\
\hline Gapdh & CTGACGTGCCGCCTGGAGAA & CCCCGGCATCGAAGGTGGAA \\
\hline
\end{tabular}


A

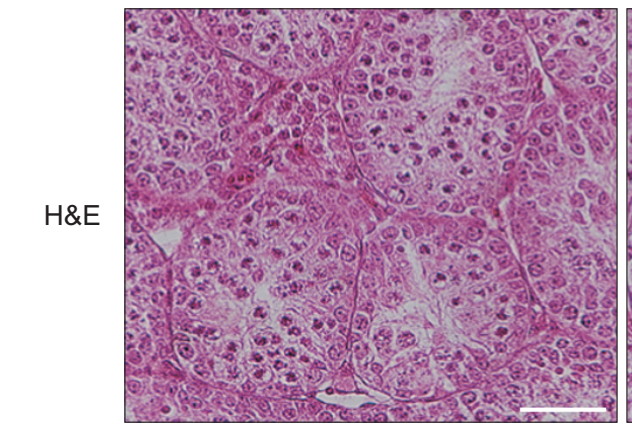

Pup testis

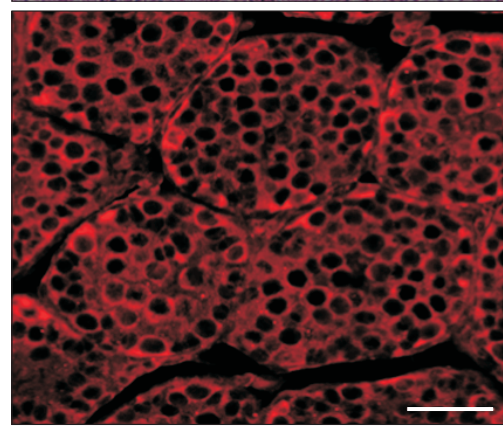

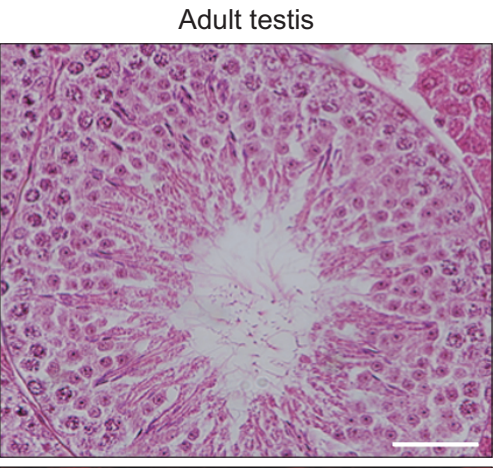

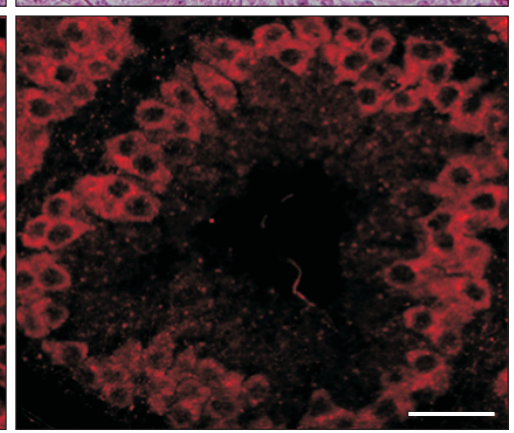

B

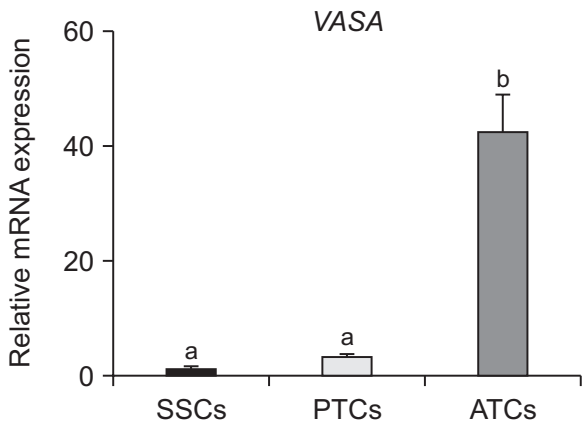

Fig. 1. Expression of Vasa in pup and adult testes. (A) Detection of pup and adult testis morphology by H\&E staining. The pup testes had smaller seminiferous tubules than the adult testes. The Vasa protein was expressed in cytoplasm of both pup and adult testes. Scale bar $=$ $100 \mu \mathrm{m}$. (B) Analysis of Vasa gene expression using qRT-PCR. The Vasa gene was highly expressed in adult testicular cells (ATCs) compared with cultured spermatogonial stem cells (SSCs) and pup testicular cells (PTCs). These data were normalized by Gapdh, and the error bars represent \pm SEM for three independent replicates. Different letters are statistically significant $(p<0.05)$.

\section{Differential expression of undifferentiated spermatogonial stem cell-associated genes}

qRT-PCR was performed to analyze the expression of undifferentiated SSC-related genes in cultured SSCs, PTCs, and ATCs (Fig. 2). The expression of undifferentiated SSC marker genes Pax7, Plzf, Gfra1, Etv5, and Bcl6b showed a significant increase in SSCs (enriched undifferentiated SSCs).

\section{Differential expression of differentiated spermatogonial stem cell-associated genes}

Additionally, the expression of differentiation-related marker genes, such as c-kit and Stra8, was verified (Fig. 3). c-kit gene expression was significantly increased in ATCs compared to in SSCs and PTCs. However, there was no significant difference between SSCs and PTCs. The Stra8 gene was highly expressed in PTCs and ATCs compared to in SSCs.

\section{DISCUSSION}

This study confirmed gene expression profiling of rela- tive spermatogenesis during postnatal periods. Three types of cells were used to identify gene expression. qRTPCR analysis showed high expression of undifferentiated genes in SSCs. However, lower expression levels of differentiated genes were found compared with PTCs and ATCs. SSCs were isolated from pup testes tissue and sorted using Thy1 antibody to obtain an enriched cell population for SSCs. In many previous studies, Thy1 was used to separate the mouse SSCs (Karmakar et al., 2017; Jung et al., 2020b). In addition, it was found that the Pax7 gene was expressed at higher levels in SSCs than in PTCs. The Pax7 gene is limited to $A_{s}$ undifferentiated SSCs (Aloisio et al., 2014). Therefore, the population of undifferentiated $A_{s}$ spermatogonia was enriched. In addition, the transcription factor gene Plzf (also known as ZBTB16) is involved in the regulation of self-renewal and the maintenance of stem cells (Costoya et al., 2004). It is expressed by all undifferentiated $A_{s}, A_{p r}, A_{a l 4}, A_{a l 8}$, and $A_{a 116}$ spermatogonia. However, the GFRa1 gene is expressed only in $\mathrm{A}_{\mathrm{s}}, \mathrm{A}_{\mathrm{pr}}$, and $\mathrm{A}_{\text {al4 }}$ spermatogonia (Hara et al., 2014), and plays an important role in undifferentiated SSCs. Here, our results showed that Plzf was not significantly expressed between 

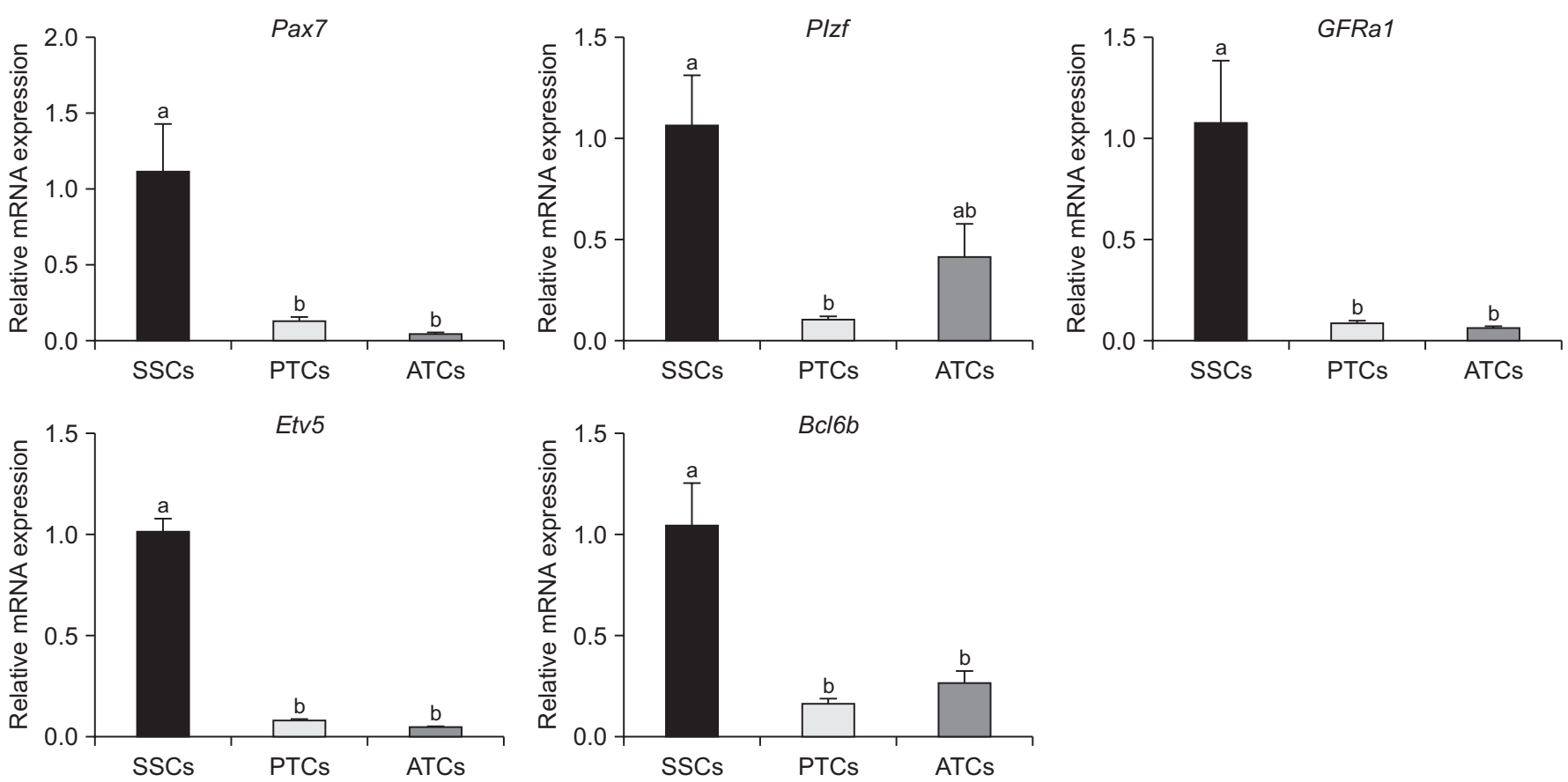

Fig. 2. Analysis of undifferentiated spermatogonial stem cell (SSC)-associated gene expression using qRT-PCR. $A_{\text {single }}\left(A_{s}\right)$ specific expression gene, Pax7, was highly expressed in cultured SSCs. Additionally, the expression of undifferentiated marker genes PIzf, GFRa1, Etv5, and Bcl6b was significantly increased in SSCs compared with pup testicular cells (PTCs) and adult testicular cells (ATCs). These data were normalized by Gapdh, and the error bars represent \pm SEM for three independent replicates. Different letters are statistically significant $(p<0.05)$.
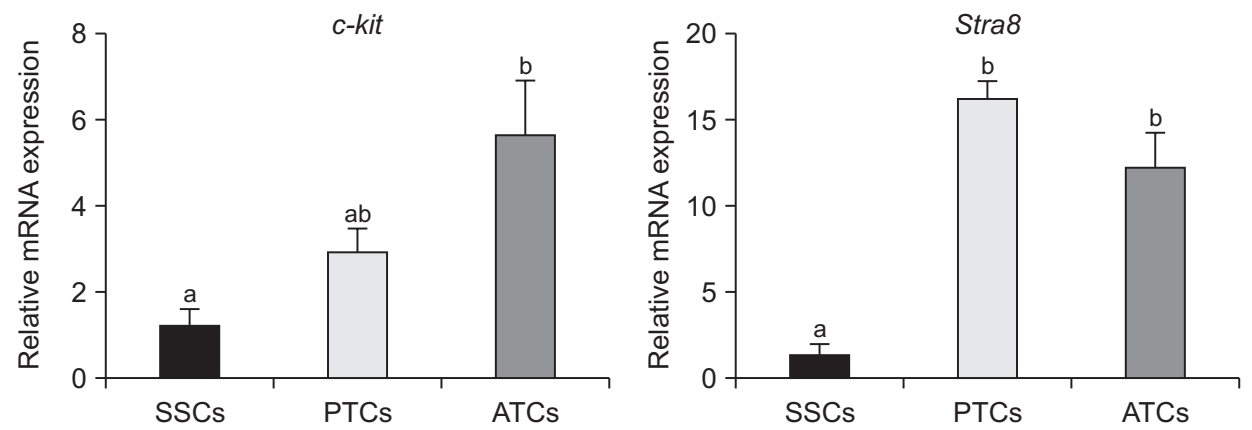

Fig. 3. Analysis of differentiated spermatogonial stem cell (SSC)-associated gene expression using qRT-PCR. The expression of undifferentiated marker genes $c^{-k i t}$ and Stra8 was significantly increased in pup testicular cells (PTCs) and adult testicular cells (ATCs) compared to in SSCs. These data were normalized by Gapdh, and the error bars represent \pm SEM for three independent replicates. Different letters are statistically significant $(p<0.05)$.

SSCs and ATCs. The results also indicated that GFRa1 was more appropriate than Plzf, which uses undifferentiated markers. Both Etv5 and Bcl6b are associated with glial cell line-derived neurotrophic factor (GDNF)-regulation, selfrenewal, and proliferation in SSCs (Oatley et al., 2006; Wu et al., 2011). These genes were highly expressed in SSCs, such as the GFRa1 gene. Therefore, it is a useful marker for the detection of undifferentiated SSCs.

Auharek and França (2010) reported that 5-day-old male mice consist of approximately 20,000 undifferenti- ated spermatogonia and an extremely small population of differentiated spermatogonia (Auharek and de França, 2010). In contrast, 100-day-old male mice have a similar undifferentiated spermatogonia cell population with young-aged mice but have more than 400,000 cells of differentiated spermatogonia. The PTCs were isolated from pup testes without sorting by Thy1, which consists of whole testicular cells. As a result, PTCs appeared to have lower expression of undifferentiation genes but higher expression of differentiation genes. We found that 


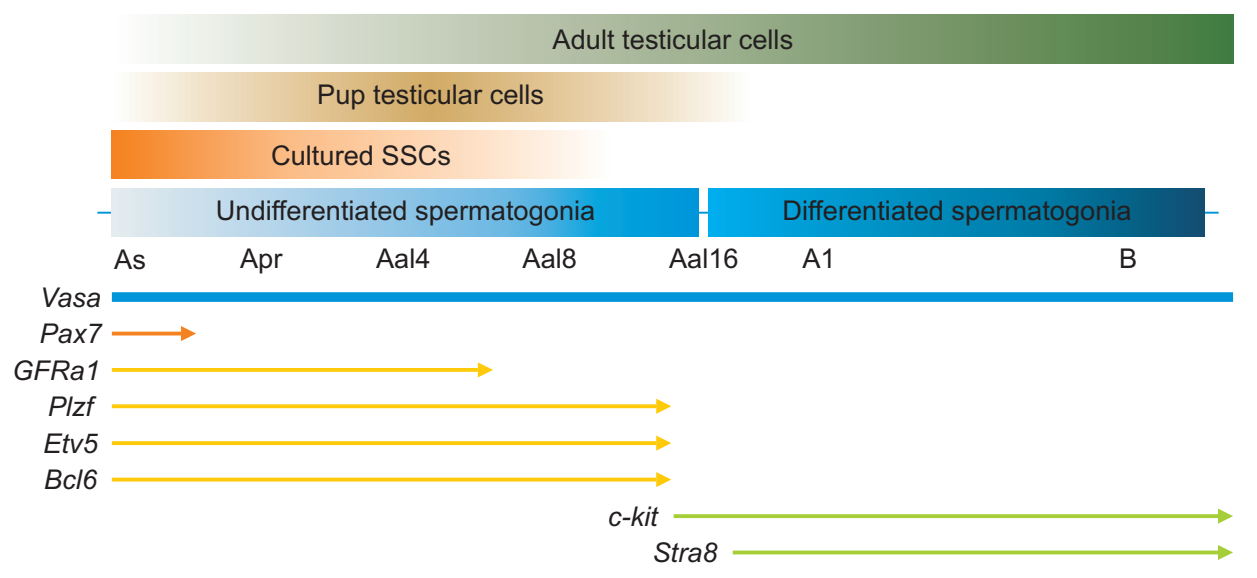

Fig. 4. Schematic overview of the gene expression analysis of spermatogenesisassociated genes in cultured spermatogonial stem cells (SSCS), pup testicular cells (PTCS), and adult testicular cells (ATCS). the PTCs contained more differentiated cells than undifferentiated cells compared with cultured SSCs (germ cells enriched for SSCs through in vitro culture). The $c$-kit gene is involved in differentiating $A_{a l}$ and $A_{1}$ spermatogonia, which differentiate from $A_{a l}$ to $A_{1}$ spermatogonia (Yoshinaga et al., 1991; Schrans-Stassen et al., 1999). These results suggest that PTCs may be used as an indication of the middle stage between $A_{a l}$ and $A_{1}$ spermatogonia. Retinoic acid is promoted by the differentiation of undifferentiated spermatogonia, which is stimulated by retinoic acid-8 (Stra8) gene, which is involved in the first round of meiotic spermatogenesis ( $\mathrm{Li}$ et al., 2011) and is expressed in preleptotene spermatocytes (Zhou et al., 2008). Our results indicated that the differentiated marker Stra8 was higher expressed in PTCs and ATCs than in cultured SSCs.

In conclusion, this study demonstrated the expression of undifferentiated and differentiated spermatogonia marker genes in postnatal periods. As shown in Fig. 4, we focused on the expression of several marker genes in postnatal periods, including cultured SSCs. The results of this study provide the characteristics of, and aid in the understanding of, the various spermatogenesis stages that involve the fate decisions and differentiation of SSCs. In addition, it is a useful tool for the verification of spermatogenesis using spermatogenesis-associated marker genes.

\section{CONFLICTS OF INTEREST}

No potential conflict of interest relevant to this article was reported.

\section{AUTHOR CONTRIBUTIONS}

Conceptualization: Buom-Yong Ryu

Data curation: Buom-Yong Ryu, Jin Seop Ahn

Formal analysis: Jin Seop Ahn

Funding acquisition: Buom-Yong Ryu

Investigation: Hyun-Sung Ryu, Jin Seop Ahn, Sang-Eun Jung

Methodology: Hyun-Sung Ryu, Beom-Jin Shin, Jong-

Hyun Won, Tea Gun Um, Seo-Hee Kim

Project administration: Buom-Yong Ryu

Resources: Sang-Eun Jung, Beom-Jin Shin

Software: Hyun-Sung Ryu, Tea Gun Um

Supervision: Buom-Yong Ryu

Validation: Jin Seop Ahn, Sang-Eun Jung

Visualization: Huijo Oh, Jong-Hyun Won

Writing - original draft: Jin Seop Ahn

Writing - review \& editing: Jin Seop Ahn, Buom-Yong Ryu

\section{AUTHOR'S POSITION AND ORCID NO.}

JS Ahn, Research Professor, https://orcid.org/0000-0001-9244-0561

HS Ryu, B.S. Student,

https://orcid.org/0000-0002-5278-9635

SE Jung, Ph.D Researcher, https://orcid.org/0000-0003-1153-2195

BJ Shin, Ph.D Student, https://orcid.org/0000-0001-9298-6169

JH Won, M.S. Student, https://orcid.org/0000-0002-6902-1665

TG Um, M.S. Student, https://orcid.org/0000-0001-7715-0128 
H Oh, M.S. Student,

https://orcid.org/0000-0003-4508-2313

SH Kim, M.S. Student,

https://orcid.org/0000-0003-2820-4745

BY Ryu, Professor,

https://orcid.org/0000-0002-8349-7299

\section{REFERENCES}

Aloisio GM, Nakada Y, Saatcioglu HD, Peña CG, Baker MD, Tarnawa ED, Mukherjee J, Manjunath H, Bugde A, Sengupta AL, Amatruda JF, Cuevas I, Hamra FK, Castrillon DH. 2014. PAX7 expression defines germline stem cells in the adult testis. J. Clin. Invest. 124:3929-3944.

Auharek SA and de França LR. 2010. Postnatal testis development, Sertoli cell proliferation and number of different spermatogonial types in C57BL/6J mice made transiently hypoand hyperthyroidic during the neonatal period. J. Anat. 216:577-588.

Buageaw A, Sukhwani M, Ben-Yehudah A, Ehmcke J, Rawe VY, Pholpramool C, Orwig KE, Schlatt S. 2005. GDNF family receptor alphal phenotype of spermatogonial stem cells in immature mouse testes. Biol. Reprod. 73:1011-1016.

Chen C, Ouyang W, Grigura V, Zhou Q, Carnes K, Lim H, Zhao GQ, Arber S, Kurpios N, Murphy TL, Cheng AM, Hassell JA, Chandrashekar V, Hofmann MC, Hess RA, Murphy KM. 2005. ERM is required for transcriptional control of the spermatogonial stem cell niche. Nature 436:1030-1034.

Costoya JA, Hobbs RM, Barna M, Cattoretti G, Manova K, Sukhwani M, Orwig KE, Wolgemuth DJ, Pandolfi PP. 2004. Essential role of Plzf in maintenance of spermatogonial stem cells. Nat. Genet. 36:653-659.

Culty M. 2009. Gonocytes, the forgotten cells of the germ cell lineage. Birth Defects Res. C Embryo Today 87:1-26.

de Rooij DG. 1973. Spermatogonial stem cell renewal in the mouse. I. Normal situation. Cell Tissue Kinet. 6:281-287.

de Rooij DG and Griswold MD. 2012. Questions about spermatogonia posed and answered since 2000. J. Androl. 33:1085-1095.

Giuili G, Tomljenovic A, Labrecque N, Oulad-Abdelghani M, Rassoulzadegan M, Cuzin F. 2002. Murine spermatogonial stem cells: targeted transgene expression and purification in an active state. EMBO Rep. 3:753-759.

Hara K, Nakagawa T, Enomoto H, Suzuki M, Yamamoto M, Simons BD, Yoshida S. 2014. Mouse spermatogenic stem cells continually interconvert between equipotent singly isolated and syncytial states. Cell Stem Cell 14:658-672.

Ishii K, Kanatsu-Shinohara M, Toyokuni S, Shinohara T. 2012. FGF2 mediates mouse spermatogonial stem cell self-renewal via upregulation of Etv5 and Bcl6b through MAP2K1 activation. Development 139:1734-1743.

Jung SE, Ahn JS, Kim YH, Oh HJ, Kim BJ, Ryu BY. 2020a. Necrostatin-1 improves the cryopreservation efficiency of murine spermatogonial stem cells via suppression of necroptosis and apoptosis. Theriogenology 158:445-453.

Jung SE, Kim M, Ahn JS, Kim YH, Kim BJ, Yun MH, Auh JH, Ryu BY. 2020b. Effect of equilibration time and temperature on murine spermatogonial stem cell cryopreservation. Biopreserv. Biobank. 18:213-221.

Karmakar PC, Kang HG, Kim YH, Jung SE, Rahman MS, Lee HS, Kim YH, Pang MG, Ryu BY. 2017. Bisphenol A affects on the functional properties and proteome of testicular germ cells and spermatogonial stem cells in vitro culture model. Sci. Rep. 7:11858.

Li H, Palczewski K, Baehr W, Clagett-Dame M. 2011. Vitamin A deficiency results in meiotic failure and accumulation of undifferentiated spermatogonia in prepubertal mouse testis. Biol. Reprod. 84:336-341.

Oatley JM, Avarbock MR, Brinster RL. 2007. Glial cell linederived neurotrophic factor regulation of genes essential for self-renewal of mouse spermatogonial stem cells is dependent on Src family kinase signaling. J. Biol. Chem. 282:25842-51.

Oatley JM, Avarbock MR, Telaranta AI, Fearon DT, Brinster RL. 2006. Identifying genes important for spermatogonial stem cell self-renewal and survival. Proc. Natl. Acad. Sci. U. S. A. 103:9524-9529.

Oatley JM and Brinster RL. 2006. Spermatogonial stem cells. Methods Enzymol. 419:259-282.

Oatley JM and Brinster RL. 2008. Regulation of spermatogonial stem cell self-renewal in mammals. Annu. Rev. Cell Dev. Biol. 24:263-286.

Park MH, Park JE, Kim MS, Lee KY, Yun JI, Choi JH, Lee E, Lee ST. 2014. Effects of suspension culture on proliferation and undifferentiation of spermatogonial stem cells derived from porcine neonatal testis. Reprod. Dev. Biol. 38:85-91.

Phillips BT, Gassei K, Orwig KE. 2010. Spermatogonial stem cell regulation and spermatogenesis. Philos. Trans. R. Soc. Lond. B Biol. Sci. 365:1663-1678.

Schlesser HN, Simon L, Hofmann MC, Murphy KM, Murphy T, Hess RA, Cooke PS. 2008. Effects of ETV5 (ets variant gene 5 ) on testis and body growth, time course of spermatogonial stem cell loss, and fertility in mice. Biol. Reprod. 78:483-489.

Schrans-Stassen BH, van de Kant HJ, de Rooij DG, van Pelt AM. 1999. Differential expression of c-kit in mouse undifferentiated and differentiating type A spermatogonia. Endocrinology 140:5894-5900.

Sorrentino V, Giorgi M, Geremia R, Besmer P, Rossi P. 1991. Expression of the c-kit proto-oncogene in the murine male germ cells. Oncogene 6:149-151.

Toyooka Y, Tsunekawa N, Takahashi Y, Matsui Y, Satoh M, Noce T. 2000. Expression and intracellular localization of mouse Vasa-homologue protein during germ cell development. Mech. Dev. 93:139-149.

Valli H, Phillip BT, Orwig KE, Gassei K, Nagano MC. 2015. Spermatogonial stem cells and spermatogenesis. In: Plant TM, Zeleznik AJ (Eds.), Knobil and Neill's Physiology of Reproduction. 4th ed, Academic Press, Amsterdam, pp. 595-635. 
Wu X, Goodyear SM, Tobias JW, Avarbock MR, Brinster RL. 2011. Spermatogonial stem cell self-renewal requires ETV5mediated downstream activation of Brachyury in mice. Biol. Reprod. 85:1114-1123.

Yoshinaga K, Nishikawa S, Ogawa M, Hayashi S, Kunisada T, Fujimoto T, Nishikawa S. 1991. Role of c-kit in mouse spermatogenesis: identification of spermatogonia as a specific site of c-kit expression and function. Development 113:689699 .

Zhou Q, Nie R, Li Y, Friel P, Mitchell D, Hess RA, Small C, Griswold MD. 2008. Expression of stimulated by retinoic acid gene 8 (Stra8) in spermatogenic cells induced by retinoic acid: an in vivo study in vitamin A-sufficient postnatal murine testes. Biol. Reprod. 79:35-42. 